\title{
Hecho ilícito internacional International Wrongful Act
}

\author{
Pietro Sferrazza Taibi ${ }^{* *}$ \\ Universidad Andrés Bello \\ pietrosferrazza@gmail.com \\ Recibido / received: 14/07/2017 \\ Aceptado / accepted: 28/07/2017 \\ DOI: https://doi.org/10.20318/eunomia.2017.3823
}

\section{Resumen}

En este trabajo se abordará un análisis dogmático de la noción de hecho internacionalmente ilícito en el marco de la responsabilidad internacional del Estado. Sin duda, se trata de una noción clave, dado que su configuración en un caso concreto activa la funcionalidad del resto de los capítulos de la responsabilidad internacional del Estado. En este trabajo se explicará la incidencia que ha tenido la distinción entre normas primarias y normas secundarias para la construcción del concepto de hecho internacionalmente ilícito. Asimismo, se abordará un análisis de cada uno de los dos elementos constitutivos del hecho internacionalmente ilícito, a saber, la ilicitud y la imputabilidad.

\section{Palabras clave}

Responsabilidad internacional del Estado, hecho internacionalmente ilícito, Comisión de Derecho Internacional, ilicitud, imputabilidad/atribución, normas primarias/normas secundarias.

\begin{abstract}
This paper will deal with a dogmatic analysis of the notion of internationally wrongful acts within the framework of the international responsibility of the State. Undoubtedly, this is a key notion, since its configuration in one case activates the functionality of the rest of the chapters of the State's international responsibility. The paper will explain the impact of the distinction between primary and secondary rules for the construction of the concept of internationally wrongful act. It will also address an analysis of each of the two constituent elements of the internationally wrongful act, namely, breach and attribution.
\end{abstract}

\section{Keywords}

International State responsibility, internationally wrongful act, International Law Commission, breach, imputation/attribution, primary rules/secondary rules.

SUMARIO. 1. Introducción. 2. El concepto de responsabilidad internacional por el hecho ilícito internacional. 3. El marco normativo de la responsabilidad internacional del Estado. 4. La diferenciación entre normas primarias y normas secundarias: una clasificación

\footnotetext{
** Doctor en Estudios Avanzados en Derechos Humanos (Universidad Carlos III de Madrid, España); Abogado; Licenciado en Ciencias Jurídicas (Universidad de Valparaíso, Chile), Prof. de Derecho Internacional Público de la Universidad Andrés Bello, Carrera de Derecho-Sede Viña del Mar, Facultad de Derecho, Quillota 980, Viña del Mar, Chile.
} 
revolucionaria. 5. La noción del hecho internacionalmente ilícito. 5.1.

La ilicitud. 5.2. La imputabilidad o atribución. 6. Conclusiones.

\section{Introducción}

Según Pellet (2010a, p. 3, traducción propia), la responsabilidad internacional es el "corolario del Derecho Internacional, la mejor prueba de su existencia y la medida más creíble de su eficacia". Por su parte, Ago sostuvo que si se pretende "negar la idea de responsabilidad del Estado porque supuestamente entra en conflicto con la idea de soberanía, forzosamente se niega la existencia de un ordenamiento jurídico internacional" (Comisión de Derecho Internacional, 1971, p. 205, traducción propia). Para Cançado Trindade (2013, p. 453, traducción propia), la responsabilidad internacional representa un "capítulo complejo, realmente central y fundamental del Derecho Internacional Público", ya que "el grado de consenso que se ha conseguido o no en relación con sus múltiples aspectos [...] está destinado a reflejar, en último término, el grado de evolución y cohesión de la comunidad internacional en su conjunto". Las apreciaciones de estos autores dan cuenta de la importancia que el tópico de la responsabilidad internacional ha adquirido en el Derecho Internacional Público, como una materia de alcance y aplicación general en la que se refleja el grado de coacción y eficacia de esta rama del Derecho.

En base a lo anterior, este trabajo pretende abordar la conceptualización de una noción esencial de la teoría de la responsabilidad internacional del Estado: el hecho internacionalmente ilícito. En efecto, la pregunta sobre la configuración de la responsabilidad ante un comportamiento del Estado dependerá de la existencia de un hecho internacionalmente ilícito. Por ende, el análisis de todos los otros capítulos de la teoría de la responsabilidad internacional -las consecuencias jurídicas que ésta produce, los mecanismos para hacerla efectiva, la eventual concurrencia de causales de exclusión de la ilicitud- dependerán de la presencia de un hecho ilícito.

Para abordar el objeto propuesto, en primer lugar se explicará en términos generales la noción de responsabilidad internacional del Estado y se identificará su marco normativo. Asimismo, se hará referencia a la distinción entre normas primarias y normas secundarias. Tras la exposición de estas nociones básicas, se abordará en profundidad la noción de hecho ilícito internacional, con especial referencia a cada uno de sus elementos conceptuales: la ilicitud y la imputabilidad.

2. El concepto de responsabilidad internacional por el hecho ilícito internacional

La elaboración de un concepto unívoco y general de responsabilidad internacional es una tarea compleja, porque debido a su generalidad se trata de una noción que se relaciona con un sinnúmero de temas del Derecho Internacional. Mariño Menéndez (2005, p. 473) la define como:

"un comportamiento determinado, atribuido a un sujeto de Derecho Internacional, [...] calificado por este ordenamiento como «lesivo» para derechos o intereses de terceros sujetos y, por ello, [...] considerado un hecho jurídico al cual el Derecho Internacional vincula consecuencias determinadas: dar origen a un conjunto de nuevas relaciones jurídicas («de responsabilidad») entre el sujeto al que se atribuya el hecho y el sujeto o sujetos injustamente perjudicados por el comportamiento de aquél". 
Según Stern (2010, p. 194), la responsabilidad internacional del Estado por el hecho internacionalmente ilícito se define tradicionalmente como el conjunto de obligaciones que un sujeto internacional debe cumplir como consecuencia de una acción u omisión que le es imputable. Teniendo en cuenta este concepto general, es necesario abordar una visión panorámica de su marco regulador en el Derecho Internacional, cuestión a la que se dedicará el siguiente apartado.

\section{El marco normativo de la responsabilidad internacional del Estado}

El principal instrumento normativo sobre la responsabilidad internacional del Estado es el Proyecto sobre Responsabilidad del Estado por Hechos Internacionalmente Ilícitos (en adelante, PREHII) elaborado por la Comisión de Derecho Internacional (en adelante, CDI $)^{1}$. Este instrumento es el resultado de un largo proceso codificador que se inició poco después de la creación de la CDI. En 1949, la Comisión incluyó la responsabilidad internacional entre catorce temas que debían ser objeto de un proceso general de codificación internacional (CDI, 1949, p. 281). La elaboración de esta lista fue el primer hito de una reflexión sobre la responsabilidad internacional del Estado que se prolongó por más de cincuenta años, un plazo demasiado extenso aun a pesar de la alta complejidad de la materia ${ }^{2}$.

Detallar minuciosamente el trabajo de la CDI durante este largo período de tiempo requeriría un estudio histórico-normativo que escapa del objeto del presente apartado. Sólo a modo de simplificación esquemática, cabe recordar que en el proceso de redacción del Proyecto intervinieron cinco relatores -Francisco V. García Amador, Roberto Ago, Willem Riphagen, Gaetano Arangio-Ruiz y James Crawfordque redactaron respectivos informes sobre el tópico de la responsabilidad del Estado $^{3}$. En cuanto a las etapas de trabajo, cabe señalar que un proyecto de artículos se aprobó en primera lectura en 1996 (CDI, 1996, 58-73) y que el proyecto definitivo fue aprobado en segunda lectura en 2001. La Asamblea General de Naciones Unidas (en adelante, AG) tomó nota de su aprobación mediante la resolución 56/83 del 12 de diciembre de 2001 sobre Responsabilidad del Estado por Hechos Internacionalmente llícitos ${ }^{4}$. El texto de los artículos viene acompañado por un conjunto de Comentarios elaborados por la misma CDI y que constituyen una herramienta valiosa para la interpretación de sus disposiciones (Pellet, 2010b, p. 84).

EI PREHII tiene una forma y estructura muy similar a la de un tratado internacional; sin embargo, no siendo un tratado cabe preguntarse cuál es su naturaleza normativa y si puede considerarse como un conjunto de disposiciones vinculantes para los Estados. La AG simplemente ha "tomado nota" del Proyecto mediante la resolución antes citada, expresión que no ayuda a responder la pregunta. Durante la preparación del PREHII se barajaron dos posiciones sobre la posibilidad de convertirlo en una convención internacional. La posición favorable

${ }^{1}$ El Proyecto junto con sus comentarios puede consultarse en CDI (2001).

${ }^{2}$ La CDI ha sido objeto de varias críticas (Abad, 2001, pp. 41 y 42; Boyle, 1998, pp. 11-17 y 22-24; Zemanek, 1996, p. 228). En opinión de Zemanek, "un gran órgano con un tiempo limitado para sus conclusiones es un instrumento torpe para tratar negociaciones delicadas" (1996, p. 228, traducción propia).

3 Todos los informes y el resto de las fuentes sobre los trabajos preparatorios del Proyecto pueden consultarse en la página web de la CDI, Analytical Guide to the Work of the International Law Commission. State Responsibility, International Law Commission, disponible en la siguiente dirección electrónica: http://legal.un.org/ilc/guide/9 6.shtml [fecha de consulta: 3 de julio de 2017].

${ }^{4}$ Un breve resumen de los trabajos preparatorios puede consultarse en Mariño Menéndez (2005, pp. 474-475). 
basaba sus argumentos en la alta trascendencia de la responsabilidad internacional del Estado. Por el contrario, de acuerdo con otra postura, la discusión de un tratado es un proceso largo y de resultado incierto, que incluso podría arruinar el consenso alcanzado en el seno de la CDI. Además, los miembros de la CDI temían que la estructura y el equilibrio del Proyecto fueran severamente trastocados durante la eventual negociación de un tratado. También se pensaba que el Proyecto podía tener una mayor utilidad y proyección si se iba integrando gradualmente a la práctica de los Estados, tribunales y organizaciones internacionales. Finalmente, se argumentaba que la eventual aprobación de una convención no aseguraba una aceptación amplia por parte de los Estados, quienes incluso podrían ratificar el tratado formulando reservas. En definitiva y con independencia de las críticas que se puedan plantear, la postura que prevaleció fue la que estaba en contra de convertir el Proyecto en un texto convencional. Desafortunadamente, la AG se mantuvo al margen de este debate y no hizo más que acatar la voluntad de los comisionados procediendo a tomar nota del Proyecto (Caron, 2002, pp. 861-866; Gutiérrez Espada, pp. 383-387; Pellet, 2010b, pp. 86 y 87).

Esta posición asustadiza es insostenible y los argumentos con que se pretendió justificarla carecen de sentido por estar basados en meras especulaciones. ¿Qué tratado no conlleva los riesgos antes reseñados? Las expectativas de éxito no pueden en ningún caso justificar una actitud reacia hacia la regulación convencional de una materia tan relevante, ya que, según Gutiérrez Espada:

"[e]l tratado internacional, por su naturaleza vinculante, por ser no sólo codificación sino desarrollo progresivo, por no limitarse, cuando lo hace, a codificar sin más sino que, al y por hacerlo, concreta, clarifica, pule, perfecciona en suma las normas no escritas, por su auctoritas frente a otros instrumentos internacionales, $y$, en fin porque [...] es la única manera que permite «establecer mecanismos concretos que permitan resolver las diferencias que surgen en la práctica» ante una Corte o Tribunal, es la forma idónea, más rigurosa y noble con el que el denodado esfuerzo de la CDI sobre la responsabilidad internacional debe revestirse" (2002, p. 387)".

Pese a estar de acuerdo con el espíritu de esta cita, es necesario señalar que en el presente nada permite presagiar que dentro de un corto o mediano plazo se iniciará la negociación de un tratado internacional que tome como base el PREHII. En efecto, la $A G$ ha seguido manteniendo una actitud muy tímida. Los avances destacables desde el año 2004 son la creación de un grupo de trabajo sobre el asunto, la recopilación de algunas opiniones de los Estados por parte de la Secretaría General y la compilación por parte de ésta de las decisiones de tribunales y otros órganos internacionales que han aplicado el PREHII. En cuanto al destino del Proyecto, las posiciones de los Estados siguen divididas. Tomando como punto de partida la extendida aplicación del Proyecto en la práctica internacional, algunas delegaciones estiman que debe convertirse en un tratado a fin de generar certeza jurídica sobre sus disposiciones y contribuir a la paz y la estabilidad de las relaciones internacionales. En cambio, otras delegaciones estiman que el Proyecto debe conservar su forma actual, porque muchas de sus disposiciones no han alcanzado un nivel consuetudinario y porque de negociarse un tratado el texto podría perder su armonía normativa a causa de la falta de acuerdo entre los Estados ${ }^{5}$.

Ahora bien, si el PREHII no es un tratado internacional, cabe preguntarse si es posible enmarcarlo en otra de las fuentes del Derecho internacional y cuál sería

\footnotetext{
${ }^{5}$ El resumen de este debate en el último período de sesiones de la $A G$ en que se discutió el asunto puede consultarse en AG (2016).
} 
su verdadero valor normativo en la actualidad. Las respuestas a estas preguntas no son ni claras ni definitivas. Ciñéndose a la regulación del sistema de fuentes del artículo 38 del Estatuto de la Corte Internacional de Justicia ${ }^{6}$, algunos autores han concluido que el Proyecto es un "medio auxiliar para la determinación de las reglas de Derecho", en cuanto asimilable a la doctrina de los publicistas (Brownlie, 2008, p. 25; Caron, 2002, p. 867; Crawford, 2012, p. 45). Sin embargo, Meron (1991, p. 137) ha considerado que los trabajos de la CDI constituyen una etapa en el proceso de codificación y desarrollo progresivo del Derecho internacional en el marco de Naciones Unidas, de modo que pueden servir para demostrar la práctica de Estados y organizaciones internacionales ${ }^{7}$.

No es fácil decantarse por alguna de estas posiciones. Considerar que el Proyecto es una manifestación de la doctrina implicaría restarle valor normativo, mientras que optar por el extremo de calificarlas como normas consuetudinarias es discutible, al menos, respecto a varias de sus disposiciones que no han alcanzado ese nivel. Pero con independencia de este debate, lo cierto es que el PREHII es un instrumento que paulatinamente va asumiendo cierto protagonismo en la práctica internacional, bastando como ejemplo el hecho de que varios tribunales internacionales lo utilicen como material normativo para la fundamentación de sus decisiones, entre ellos, la Corte Internacional de Justicia (Corte Internacional de Justicia, 2004, p. 136, párr. 140; Corte Internacional de Justicia, 2005, p. 168, párrs. 160 y 293$)^{8}$. En definitiva, cuando la CDI trabaja en la codificación de un tópico del Derecho internacional, procede a estudiar los antecedentes que reverberan en las fuentes, sean éstas convencionales, jurisprudenciales o de cualquiera otra índole. Se trata de un trabajo que tiende a sistematizar el Derecho vigente sobre una materia. En ese sentido y a pesar de las críticas que la CDI merece, las disposiciones del PREHII son un reflejo de una práctica internacional sobre la responsabilidad del Estado que se viene gestando hace décadas.

4. La diferenciación entre normas primarias y normas secundarias: una clasificación revolucionaria

Para la comprensión de la mecánica del Proyecto es necesario tener presente una distinción elemental entre las normas primarias y las normas secundarias. Las normas primarias son las que establecen las obligaciones internacionales a cuyo cumplimiento están obligados los sujetos de Derecho Internacional. En cambio, las normas secundarias son las que determinan cuándo se han vulnerado las normas primarias y las consecuencias que se derivan de dicho incumplimiento (Cançado Trindade, 2013, p. 457, n. 17; Gutiérrez Espada, 2005, p. 18).

EI PREHII solamente se preocupa de codificar las normas secundarias de una manera abstracta y formal, y se desentiende de las normas primarias. La idea que subyace a este enfoque halla justificación en la intención de crear un cuerpo normativo de carácter general, que sea fácilmente aplicable a toda clase de

6 Estatuto de la Corte Internacional de Justicia, disponible en la siguiente dirección electrónica: http://www.icj-cii.org/files/statute-of-the-court/statute-of-the-court-es.pdf. [fecha de consulta: 3 de julio de 2017].

7 Sobre este tema, también puede consultarse Boyle (1998, p. 18). Una buena descripción de las posiciones de la doctrina sobre el valor de los trabajos de la CDI desde la perspectiva de las fuentes del Derecho internacional puede consultarse en Sinclair (1987, p. 120-127), quien tras describir las diversas posturas sobre el punto, asume una tesis similar a la de Meron, concluyendo que los trabajos de la CDI contienen elementos de reconocimiento y comprobación del Derecho Internacional.

8 La Secretaría General de Naciones Unidas ha recopilado en varios informes los precedentes en que se ha aplicado el PREHII (AG, 2007; AG, 2010; AG, 2013; AG, 2016). 
obligación internacional. La codificación de la totalidad de las normas primarias es una tarea humanamente imposible, ya que su identificación depende de la interacción de las fuentes del Derecho Internacional. El Relator Ago fue muy perspicaz al darse cuenta de ello y asumió esta distinción como un verdadero dogma, persuadiendo a los comisionados que los esfuerzos codificadores debían centrarse en las normas secundarias ${ }^{9}$. Quizás en nuestro presente la diferenciación comentada pueda parecer muy evidente, pero no era tan clara para la doctrina de la década de los sesentas del siglo pasado. De hecho, hasta la intuición de Ago, el desarrollo dogmático de la responsabilidad internacional había quedado encorsetada en el marco de los daños causados a los extranjeros y la protección diplomática, dos ámbitos normativos conformados básicamente por normas primarias. En conclusión, tiene razón Pellet (2010b, pp. 75 y 76) cuando califica de "revolucionario" el hallazgo de Ago.

Pese a la lucidez analítica de esta distinción, se han planteado algunas críticas, porque en opinión de algunos autores no sería posible trazar una distinción tajante entre las obligaciones internacionales plasmadas en las normas primarias y las reglas de atribución contempladas en las normas secundarias (Brownlie, 2008, p. 436; Kress, 2001, p. 122, n. 122). Si bien quienes defienden la distinción aceptan parcialmente esta crítica, sostienen que no es suficiente para renunciar a la diferenciación entre ambas clases de normas desde un punto de vista analítico (CDI, 1998, p. 34; Condorelli y Kress, 2010, p. 225). El gran mérito de esta distinción estriba en haber permitido la codificación de un conjunto de principios y reglas de carácter general sobre la responsabilidad internacional del Estado. Probablemente, sin esta separación entre obligaciones y reglas de atribución hubiera sido imposible elaborar una teoría de la responsabilidad internacional aplicable a nivel general en el Derecho Internacional. Es sobre la base de esta distinción que se ha elaborado el concepto de hecho internacionalmente ilícito, tal como se verá a continuación.

\section{La noción del hecho internacionalmente ilícito}

El hecho internacionalmente ilícito es el pilar de la responsabilidad internacional del Estado, el motor que da vida al resto de los temas que integran la teoría sobre esta clase de responsabilidad. En base al artículo 2 del PREHII, el hecho internacionalmente ilícito puede conceptualizarse como una acción u omisión imputable al Estado que viola una obligación internacional vigente (Gutiérrez Espada, 2005, p. 39; Gutiérrez Espada y Cervell, 2008, pp. 502 y 503; Mariño Menéndez, 2005, pp. 477 y 478). La lectura de la definición del hecho ilícito permite inferir que está integrada por dos elementos: el comportamiento imputable y la ilicitud del mismo (Corte Internacional de Justicia, 1980, párr. 56). Tradicionalmente,

\footnotetext{
${ }^{9}$ Según David (2010, pp. 28 y 29), fue el comisionado Herbert Briggs quien por primera vez utilizó las expresiones "obligaciones primarias y secundarias", citando un estudio de 1929 elaborado por la Harvard Law School que se refería a la responsabilidad del Estado por los daños causados a los extranjeros o a su propiedad. De acuerdo con Pellet (2010b, pp. 76 y 77), Ago explicó esta clasificación en el curso impartido en la Academia de Derecho Internacional de La Haya en 1939 y la defendió durante todo el período en que ejerció como relator de la CDI. Para evitar confusiones, cabe señalar que esta distinción no pudo haberse inspirado en la célebre diferenciación entre normas primarias y normas secundarias elaborada por H. L. A. Hart (1994, p. 81). Aunque comparten la terminología, la distinción de Hart se refiere a una cuestión parcialmente distinta, en cuanto las normas primarias son normas de conducta de hacer o no hacer, mientras que las normas secundarias confieren potestades que pueden incidir en la modificación o creación de las normas primarias. Por lo demás, las fechas no coinciden, ya que la primera publicación de esta obra maestra de la filosofía del Derecho se remonta a 1961, fecha muy posterior al año en que Ago dictó su curso en la Academia de Derecho Internacional de La Haya.
} 
el primero ha sido denominado elemento subjetivo y el segundo, elemento objetivo. Sin embargo, se trata de una terminología inexacta, porque la subjetividad u objetividad del acto dependen de la norma primaria y de las circunstancias de cada hecho particular (Gutiérrez Espada, 2005, p. 49; Gutiérrez Espada y Cervell, 2008, pp. 502 y 503; Przetacznik, 1983, p. 70; CDI, 2001, p. 35, art. 2, comentario $n^{\circ} 3$ ).

Existe cierta discusión sobre el orden lógico que debe seguirse al analizar la concurrencia de ambos elementos. Parece ser más adecuado comenzar con la constatación de la ilicitud y luego continuar con la atribución (Stern, 2010, p. 202). Desde el punto de vista lógico, se valora primero si se ha infringido una obligación internacional y luego se determina si la infracción es imputable al Estado ${ }^{10}$, puesto que si en la primera de ambas valoraciones se descarta la existencia de una ilicitud, la segunda valoración sobre la imputabilidad no tiene sentido, porque no podría imputarse algo que no existe. Desde el punto de vista normativo, el análisis de la imputabilidad no es una cuestión exclusivamente de hecho, sino una operación abstracta y compleja que se traduce en un juicio valorativo sobre la base de reglas normativas. En otras palabras, la plausibilidad normativa de la imputabilidad depende de la existencia de una infracción, debido a que en ausencia de la misma, no parece lógico que el operador jurídico se adentre en la valoración de la imputabilidad. Aclarado este punto se analizará brevemente en qué consiste cada uno de los elementos conceptuales del hecho internacionalmente ilícito.

\subsection{La ilicitud}

La ilicitud es la disconformidad, violación o vulneración de una obligación internacional, que se genera por un hecho de un Estado. La determinación de la ilicitud se realiza en relación con el Derecho Internacional. Como bien exponen Gutiérrez Espada y Cervell Hortal (2008, p. 516), se trata de un "principio con dos caras [porque] un hecho sólo es ilegal cuando el Derecho internacional así lo decide" y porque "un Estado no puede alegar su Derecho interno como causa que justifique el incumplimiento del Derecho internacional"11.

El comportamiento, acto o hecho del Estado es el núcleo de la ilicitud ${ }^{12}$. Dependiendo de la norma primaria, puede consistir en una acción, una omisión o una combinación de ambas (Przetacznik, 1983, pp. 72-73; CDI, 2001, pp. 35 y 36, art. 2, comentario $n^{\circ} 4$ ). La diferenciación entre acción y omisión es determinante para valorar si se ha infringido una obligación. En principio, las obligaciones de hacer se infringen mediante una omisión, a diferencia de las obligaciones de no hacer, que se vulneran mediante una acción ${ }^{13}$.De acuerdo con el artículo 12 del

$10 \mathrm{El}$ art. 2 del PREHII se refiere primero a la atribución y luego a la ilicitud. Según Przetacznik (1983, pp. 72 y 75) y Stern (2010, pp. 201 y 202), el orden del Proyecto es correcto. En cambio, para Dupuy (1999, p. 25) los elementos están invertidos. Ésta última parece ser la opinión más acertada.

${ }^{11}$ En el mismo sentido se pronuncia el PREHII en su art. 3, comentario $n^{\circ} 1$ (CDI, 2001, p. 37). La imposibilidad de invocar el Derecho interno como una justificante de la infracción deriva del art. 27 de la Convención de Viena sobre el derecho de los tratados, A/CONF.39/27 (1969), 23 de mayo de 1969, entrada en vigor el 27 de enero de 1980.

12 Como bien señala Mariño Menéndez (2005, p. 477), no hay claridad sobre la nomenclatura más adecuada para identificar el objeto de la ilicitud. El autor prefiere el término "hecho" en cuanto comprensivo de una acción y una omisión.

13 Esta diferenciación puede ser útil para identificar la conducta que el Estado debe ejecutar para hacer cesar la infracción, ya que si la infracción ha consistido en una omisión, el acto que debe hacer cesar dicha infracción será idéntico al contenido de la obligación infringida. A su vez, si la infracción consiste en una acción, para su cesación se requerirá un 
PREHII, la fuente jurídica de la obligación internacional es indiferente para los efectos de la configuración de la ilicitud, de modo que la obligación puede derivar de un tratado internacional, una regla consuetudinaria, un principio general del Derecho, un acto unilateral del Estado, una decisión vinculante de un tribunal internacional o una resolución obligatoria decretada por una organización internacional (Przetacznik, 1983, pp. 74; Nishimura, 2010, pp. 366-368; CDI, 2001, p. 58 , art. 12 , comentario $n^{\circ} 3$ y p. 36 , art. 2 , comentario $n^{\circ} 7$ ). Los Comentarios del PREHII aclaran que tampoco es relevante la naturaleza o jerarquía de la obligación violada, de modo que la responsabilidad de los Estados puede nacer de la violación de obligaciones de carácter bilateral o de obligaciones para con algunos Estados o para la comunidad internacional en su conjunto ${ }^{14}$. En este orden de ideas, el tipo o clase de obligación internacional tampoco incide en la ilicitud, con lo cual no es influyente que la obligación infringida sea más o menos concreta, de hacer o no hacer, de medio o resultado (Economides, 2010, pp. 371 y 372). Finalmente, el objeto o contenido de la obligación internacional tampoco es decisivo, de modo que no es necesario que el comportamiento objeto de la infracción se describa en los mismos términos de la obligación violada (CDI, 2001, p. 59, art. 12, comentario $\mathrm{n}^{\circ}$ 10).

La única circunstancia relevante para la configuración de la ilicitud es la vigencia de la obligación internacional al momento en que se produce el comportamiento estatal que la vulnera. Así lo impone el principio del Derecho intertemporal o de irretroactividad, consagrado en el artículo 13 del PREHII y, anteriormente, en el artículo 28 de la Convención de Viena sobre el Derecho de los Tratados (CDI, 2001, p. 60, art. 13, comentario $\mathrm{n}^{\circ} 1$ ).

Sobre este punto es conveniente realizar algunas observaciones. En primer lugar, el Derecho aplicable será el que estaba vigente al momento de la producción del hecho, con independencia del periodo en que se presente la reclamación y se substancie el procedimiento destinado a resolver el asunto (Stern, 2010, p. 216; Tavernier, 2010, p. 400). Por lo tanto, la ilicitud subsiste si con posterioridad a la comisión del hecho la obligación internacional deja de tener vigencia (Gutiérrez Espada, 2005, pp. 63 y 64; Stern 2010, p. 216; Tavernier, 2010, p. 399; CDI, 2001, pp. 61 y 62, art. 13, comentarios $n^{\circ} 7-8$ ). Esta regla no debe confundirse con la prescripción de la responsabilidad internacional, institución a la que el Proyecto presta poca atención, destinándole una sola y ambigua disposición -el art. 45conforme a la cual la responsabilidad internacional se prolonga indefinidamente en el tiempo, salvo que el Estado lesionado consienta en la extinción o haya resultado gravemente perjudicado por la demora en la presentación de la reclamación (Gutiérrez Espada, 2005, pp. 64 y 65; CDI, 2001, pp. 130-132, art. 45, cometarios 6$11)^{15}$. En segundo lugar, la determinación del momento en que se ha vulnerado la obligación incide en muchas otras cuestiones relevantes. Salmon (2010, p. 383) ha elaborado una lista de temas sobre los que repercute la determinación del momento de la infracción, entre otros, la operatividad de la protección diplomática, la valoración del perjuicio para los efectos de la reparación, la activación de la jurisdicción de un tribunal internacional, el carácter nacional o internacional de una reclamación, la admisibilidad de la acción y la ya mencionada prescripción.

comportamiento diferente de la obligación infringida que no será necesariamente una omisión (Letty, 2010, pp. 355-363).

14 Vid. PREHII, art. 12, comentario $\mathrm{n}^{\circ} 6$, en el que se aclara que la violación de normas imperativas del Derecho internacional general genera consecuencias especiales (CDI, 2001, p. 58).

${ }^{15}$ Esta norma, tal como lo aclara en el comentario 1 al art. 45 del PREHII (CDI, 2001, p. 130) se inspiró en el art. 45 de la Convención de Viena sobre el derecho de los tratados, cit., que se remite al saneamiento de los tratados. 


\subsection{La imputabilidad o atribución}

El Estado es una entidad abstracta y colectiva cuyo comportamiento no puede llevarse a cabo sin la actuación de sus órganos. A su vez, éstos últimos están integrados por personas naturales que ejecutan fácticamente el hecho. Por lo tanto, la imputabilidad o atribución es una operación jurídica que tiene por objeto determinar si el comportamiento activo u omisivo de una persona física o jurídica puede considerarse un acto del Estado (Condorelli y Kress, 2010, p. 221; Mariño Menéndez, 2005, pp. 478 y 479; Przetacznik, 1983, p. 71) ${ }^{16}$.

EI PREHII destina el capítulo II de la Primera Parte a la regulación de esta materia, consagrando un conjunto de reglas que pretenden abarcar diferentes clases o categorías de casos. En términos generales, la imputabilidad razona sobre la base de una regla general que consiste en el principio de unidad del Estado y un conjunto de reglas excepcionales. De conformidad con el principio de unidad del Estado, toda acción u omisión de un órgano público cometido en calidad de tal es atribuible al Estado al que pertenece ese órgano (CDI, 2001, p. 41, art. 4). El fundamento último de esta regla de atribución es el principio de soberanía, ya que si el Estado tiene la facultad para poder organizar libremente su estructura orgánica es evidente que los hechos ilícitos cometidos por sus órganos le son imputables (Momtaz, 2010, p. 239). El tipo de órgano que incurre en el ilícito es irrelevante para la aplicación de esta regla de atribución (CDI, 2001, p. 41, art. 4, comentario 5), pudiendo tratarse de todo tipo de entidad individual o colectiva, persona natural o jurídica (CDI, 2001, pp. 41-44, art. 4, comentarios 6 y 12), con independencia de la jerarquía (CDI, 2001, p. 42, art. 4, comentario 7), naturaleza de funciones (CDI, 1973, p. 57), nivel territorial (Comisión de Conciliación Franco-Italiana, 2006, pp. 150-170) o pertenencia al Poder Judicial, Ejecutivo o Legislativo (CDI, 2001, pp. 4142 , art. 4, comentario 6).

El resto de las reglas de imputabilidad consagradas en el PREHII tienen por objeto permitir la atribución de una ilicitud a un Estado en supuestos en que el principio de unidad no es aplicable. De ese modo, se hace referencia al caso de entidades que sin formar parte del Estado ejercen atribuciones del poder público (art. 5) y al de los órganos de un Estado puestos a disposición de otro Estado (art. 6). También se alude a la imputabilidad de los actos ultra vires, esto es, aquellos cometidos por un órgano o funcionario del Estado fuera de su competencia o incumpliendo instrucciones (art. 7). El resto de las reglas se refiere a la imputabilidad de hechos cometidos por entidades no estatales. De ese modo, se hace referencia a la regla del control e instrucciones (art. 8), a los casos de ausencia de una autoridad oficial (art. 9), a una serie de reglas aplicables a hechos de movimientos insurreccionales (art. 10) y a la aceptación de un hecho como propio por parte del Estado (art. 11).

\section{Conclusiones}

\footnotetext{
${ }^{16}$ Según el comentario $\mathrm{n}^{\circ} 2$ del art. 2(a) del PREHII (CDI, 2001, p. 35), se optó por la utilización del término "atribución", a pesar de que la palabra "imputación" era bastante recurrente en la jurisprudencia. Esta elección se justifica porque el primero de estos términos "no supone en modo alguno que el proceso jurídico de relacionar un comportamiento con el Estado sea una ficción" (CDI, 2001, p. 37, art. 2, comentario 12). En la doctrina, Przetacznik (1983, p. 72) comparte esta elección. Por el contrario, Gutiérrez Espada (2005, p. 84) prefiere el término "imputación" por su carácter técnico. A su vez, según Condorelli y Kress (2010, p. 223), la elección de uno u otro término no acarrea consecuencias prácticas trascendentes.
} 
Con independencia de la discusión sobre el carácter más o menos vinculante del PREHII y a pesar de la incertidumbre sobre su destino, este trabajo permite concluir que, de acuerdo al estado actual de la discusión, el hecho internacionalmente ilícito es una noción imprescindible para la teoría sobre la responsabilidad internacional. El análisis o valoración del resto de los componentes de esta teoría, en efecto, dependerán inevitablemente de la configuración de un hecho internacionalmente ilícito. Razonando en base a la lógica de la distinción entre las normas primarias y normas secundarias, esta noción pretende otorgar un marco general en virtud del cual se puedan identificar las ilicitudes imputables a los Estados con independencia de la naturaleza jurídica del deber internacional infringido o de la fuente del Derecho Internacional de la que deriva. Así, la regulación de sus dos compontes, la ilicitud y la imputabilidad, pretende asentar un conjunto de criterios generales que guíen al intérprete en la valoración de una eventual infracción del Derecho Internacional. Con independencia de las discusiones que se han suscitado sobre el contenido de estos elementos -sobre todo en cuanto la entidad de ciertas reglas de imputabilidad-, la noción del hecho internacionalmente ilícito sigue teniendo plausibilidad analítica, por lo que un buen manejo de sus contornos conceptuales es necesario para valorar su configuración en un caso concreto.

\section{Bibliografía}

ABAD CASTELOS, M. (2001), "El avance sectorial, la fragmentación del orden jurídico y sus riesgos: ¿está a salvo la unidad del Derecho internacional?", Anuario da Facultade de Dereito da Universidade da Coruña, $n^{\circ} 5$, pp. 35-56.

ASAMBLEA GENERAL (2007), Responsabilidad del Estado por hechos internacionalmente ilícitos. Compilación de las decisiones de cortes, tribunales y otros órganos internacionales, Informe del Secretario General, A/62/62.

ASAMBLEA GENERAL (2010), Responsabilidad del Estado por hechos internacionalmente ilícitos. Compilación de las decisiones de cortes, tribunales y otros órganos internacionales, Informe del Secretario General, A/65/76.

ASAMBLEA GENERAL (2013), Responsabilidad del Estado por hechos internacionalmente ilícitos. Compilación de las decisiones de cortes, tribunales y otros órganos internacionales, Informe del Secretario General, A/68/72.

ASAMBLEA GENERAL (2016), Sexta Comisión, Seventy-first session. Responsibility of States for Internationally Wrongful Acts (Agenda item 74), disponible en la siguiente dirección electrónica: http://www.un.org/en/ga/sixth/71/resp of states.shtml. [fecha de consulta: 1 de julio de 2017].

ASAMBLEA GENERAL (2016), Responsabilidad del Estado por hechos internacionalmente ilícitos. Compilación de las decisiones de cortes, tribunales y otros órganos internacionales, Informe del Secretario General, A/71/80.

BOYLE, A. E. et. al. (1998), The International Law Commission and the Future of International Law, The British Institute for International and Comparative Law, Londres.

BROWNLIE, I. (2008), Principles of Public International Law, $7^{\text {a }}$ ed., Oxford University Press, Oxford.

CANÇADO TRINIDADE, A. A. (2013), International Law for Humankind. Toward a New Jus Gentium, $2^{\mathrm{a}}$ ed., Martinus Nijhoff Publishers, Leiden-Boston.

CARON, D. (2002), "The ILC Articles on State Responsibility: the Paradoxical Relationship between Form and Authority", American Journal of International Law, vol. 96, issue 2, pp. 857-873.

COMISIÓN DE CONCILIACIÓN FRANCO-ITALIANA (2006), "Différend Héritiers de S.A.R. Mgr le Duc de Guise, Décisions nos 43, 87, 107 et 162, 3 April, 18 
December 1950, 15 September 1951 and 20 November 1953", Reports of International Arbitral Awards, vol. XIII, pp. 150-170, disponible en la siguiente dirección electrónica: http://legal.un.org/riaa/cases/vol XIII/150170 Heritiers.pdf [fecha de consulta: 1 de julio de 2017].

COMISIÓN DE DERECHO INTERNACIONAL (1949), "Report to the General Assembly", Yearbook of the International Law Commission, 1949, pp. 277-290.

COMISIÓN DE DERECHO INTERNACIONAL, Analytical Guide to the Work of the International Law Commission. State Responsibility, International Law Commission, disponible en la siguiente dirección electrónica: http://legal.un.org/ilc/guide/9 6.shtml [fecha de consulta: 3 de julio de 2017].

COMISIÓN DE DERECHO INTERNACIONAL (1971), "Document A/CN.4/246 and Add.1-3: Third report on State responsibility, by Mr. Roberto Ago, Special Rapporteur-The internationally Wrongful Act of the State, Source of International Responsibility ", Yearbook of International Law Commission, vol. II (1), pp. 199274.

COMISIÓN DE DERECHO INTERNACIONAL (1973), "State responsibility", Yearbook of International Law Commission, vol. I. COMISIÓN DE DERECHO INTERNACIONAL (1989), "Second Report of the Special Rapporteur, Mr. Gaetano Arangio-Ruiz", Yearbook of International Law Commission, vol. II(1), pp. 1-58.

COMISIÓN DE DERECHO INTERNACIONAL (1996), "Draft articles on State responsibility. 1. Text of the Draft Articles Provisionally Adopted by the Commission on First Reading", Yearbook of the International Law Commission, vol. II (2), pp. 58-73.

COMISIÓN DE DERECHO INTERNACIONAL (1998), "First report on State responsibility, by Mr. James Crawford, Special Rapporteur", Document A/CN.4/490 and Add. 1-7, 24 de Abril, 1, 5, 11 y 26 de mayo, 22 y 24 de Julio, 12 de Agosto de 1998, Yearbook of the International Law Commission, vol. II(1), pp. 1-80.

COMISIÓN DE DERECHO INTERNACIONAL (2001), "Informe de la Comisión de Derecho Internacional sobre la labor realizada en el quincuagésimo tercer período de sesiones ( 23 de abril a $1^{\circ}$ de junio y 2 de julio a 10 de agosto de 2001)", Anuario de la Comisión de Derecho Internacional, vol. II, segunda parte, p. 1-223.CONDORELLI, L. y KRESS, C. (2010), "The Rules of Attribution: General Considerations". En: CRAWFORD, J., PELLET, A. y OLLESON, S. (eds.), The Law of International Responsibility, Oxford, Oxford University Press, pp. 221-236.

CORTE INTERNACIONAL DE JUSTICIA (1980), United States Diplomatic and Consular Staff in Tehran, Judgment, 24 de mayo de 1980, I.C.J. Reports, p. 3.

CORTE INTERNACIONAL DE JUSTICIA (2004), Legal Consequences of the Construction of a Wall in the Occupied Palestinian Territory, Advisory Opinion, I.C.J. Reports, p. 136.

CORTE INTERNACIONAL DE JUSTICIA (2005), Armed Activities on the Territory of the Congo (Democratic Republic of the Congo vs. Uganda), Judgment, 19 de Diciembre de 2005, I.C.J. Reports, p. 168.

CRAWFORD, J. (2004), Los artículos de la Comisión de Derecho Internacional sobre la responsabilidad Internacional del estado, Dykinson, Madrid.

CRAWFORD, J. (2012), Brownlie's Principles of Public International Law, $8^{a}$ ed., Oxford University Press, Oxford.

DAVID, E. (2010), "Primary and Secondary Rules". En: CRAWFORD, J., PELLET, A. y OLLESON, S. (eds.), The Law of International Responsibility, Oxford, Oxford University Press, pp. 27-33.

DUPUY, P.-M. (1998), "Infraction (Droit International Public)". En : GÜNCÜ, O. (col.), Répertoire de Droit International, 3 vols., Paris, Dalloz, t. II, pp. 1-8.

ECONOMIDES, C. P. (2010), "Content of the Obligation: Obligations of Means and 
Obligations of Result". En: CRAWFORD, J., PELLET, A. y OLLESON, S. (eds.), The Law of International Responsibility, Oxford, Oxford University Press, pp. 372-381.

GUTIÉRREZ ESPADA, C. (2002), "Por una responsabilidad «responsable» (a propósito del Proyecto definitivo de artículos de la CDI sobre la responsabilidad internacional del Estado por hechos ilícitos)". En: MARIÑO MENÉNDEZ, F. (ed.), El Derecho internacional en los albores del siglo XXI. Homenaje al profesor Juan Manuel Castro-Rial Canosa, Madrid, Trotta, pp. 369-391.

GUTIÉRREZ ESPADA, C. (2005), El hecho ilícito internacional, Dykinson, Madrid.

GUTIÉRREZ ESPADA, C. y CERVELL HORTAL, M. J. (2008), El Derecho Internacional en la encrucijada. Curso general de Derecho Internacional Público, $2^{\mathrm{a}}$ ed., Trotta, Madrid.

HART, H. L. A. (1994), The Concept of Law, $2^{a}$ ed., Oxford University Press, Oxford.

KRESS, C. (2001), "L'organe de facto en Droit international public. Réflexions sus l'imputation a l'état de l'acte d'un particulier a la lumière des développements récents", Revue Générale de Droit International Public, 105 (1), pp. 93-144.

LETTY, F. (2010), "Actions and Omissions". En: CRAWFORD, J., PELLET, A. y OLLESON, S. (eds.), The Law of International Responsibility, Oxford, Oxford University Press, pp. 355-363.

MARIÑO MENÉNDEZ, F. (2005), Derecho Internacional Público. Parte General, $4^{\mathrm{a}}$ ed., Trotta, Madrid.

MERON, T. (1991), Human Rights and Humanitarian Norms as Customary Law, Oxford University Press, Oxford.

MOMTAZ, D. (2010), "Attribution of Conduct to the State: State Organs and Entities Empowered to Exercise Elements of Governmental Authority". En: CRAWFORD, J., PELLET, A. y OLLESON, S. (eds.), The Law of International Responsibility, Oxford, Oxford University Press, pp. 237-246.

NISHIMURA, Y. (2010), "Source of the Obligation". En: CRAWFORD, J., PELLET, A. y OLLESON, S. (eds.), The Law of International Responsibility, Oxford, Oxford University Press, pp. 365-369.

PELLET, A. (2010a), "The Definition of Responsibility in International Law". En: CRAWFORD, J., PELLET, A. y OLLESON, S. (eds.), The Law of International Responsibility, Oxford, Oxford University Press, pp. 3-16.

PELLET (2010b), "The ILC'S Articles on State Responsibility for Internationally Wrongful Acts and Related Texts". En: CRAWFORD, J., PELLET, A. y OLLESON, S. (eds.), The Law of International Responsibility, Oxford, Oxford University Press, pp. 75-94.

PRZCETACZNIK, F. (1983), "The International Responsibility of the States for Ultra Vires Acts of their Organs", Revue de droit international, de sciences diplomatiques et politiques, vol. 61, pp. 67-80.

SALMON, J. (2010), "Duration of the Breach". En: CRAWFORD, J., PELLET, A. y OLLESON, S. (eds.), The Law of International Responsibility, Oxford, Oxford University Press, pp. 383-396.

SINCLAIR, I. (1987), The International Law Commission, Grotius Publications Limited, Cambridge.

STERN, B. (2010), "The Elements of an Internationally Wrongful Act". En: CRAWFORD, J., PELLET, A. y OLLESON, S. (eds.), The Law of International Responsibility, Oxford, Oxford University Press, pp. 193-220.

TAVERNIER, P. (2010), "Relevance of the Intentemporal Law". En: CRAWFORD, J., PELLET, A. y OLLESON, S. (eds.), The Law of International Responsibility, Oxford, Oxford University Press, pp. 397-403.

ZEMANEK, K. (1996), "Does Codification Lead to Wider Acceptance?". En: ONU, International Law as a Language for International Relations. The Hague, Kluwer Law International, pp. 224-229. 